\title{
Green-life of pink banana (Musa spp., cv. Figue Rose Naine): determination of the optimum harvesting date
}

\author{
By P.TIXIER ${ }^{1 *}$, F. SALMON ${ }^{2}$ and C. BUGAUD ${ }^{3}$ \\ ${ }^{1}$ CIRAD, UPR 26, PRAM - BP 214 - 97285 Lamentin Cedex 2, Martinique, French West Indies, \\ France \\ ${ }^{2}$ CIRAD, UPR 75, F-97130 Capesterre-Belle-Eau, Guadeloupe, French West Indies, France \\ ${ }^{3}$ CIRAD, UMR QUALISUD, PRAM - BP 214 - 97285 Lamentin Cedex 2, Martinique, French West \\ Indies, France \\ (e-mail: tixier@cirad.fr) \\ (Accepted 4 December 2009)
}

\begin{abstract}
SUMMARY
The context for the production of bananas for export is characterised by a wide range of transport-times between producer and importer countries, and by the use of a single cultivar of banana (Musa spp., AAA group, cv. Cavendish Grande Naine). We investigated the green-life of pink banana (Musa spp., AAA group, Red sub-group, cv. Figue Rose Naine) for the different physiological ages of banana fruit, measured in degree-days $\left({ }^{\circ} \mathrm{Cd}\right)$. We measured the temperature threshold of pink banana $\left(19.8^{\circ} \mathrm{C}\right)$ and showed that the green-life of pink banana decreased linearly with the physiological age of the fruit. Thus, we confirm the validity of the relationship between accumulated heat units during fruit growth and green-life that was previously established for Cavendish banana. We searched for the optimum physiological age $\left({ }^{\circ} \mathrm{Cd}\right)$ for harvest, in order to ensure a green-life that fulfilled the requirements for transport and that maximised fruit weight. For Martinique, the optimum flowering-to-harvest interval was found to be $548^{\circ} \mathrm{Cd}$, to ensure $25 \mathrm{~d}$ of green-life, as required for transport, and to maximise fruit size. We showed that fruit weight was not a good indicator on which to select bananas for harvest in order to ensure a particular green-life. This is the first time that guidance has been proposed for the transport and export of a non-Cavendish banana. These results may assist other producer countries that wish to diversify their banana exports by growing pink banana.
\end{abstract}

$\mathbf{E}$ xport bananas currently cover approx. 1 million ha, worldwide (FAOSTAT, 2005). Bananas for export are transported from the producer to the consumer in 5 -35 d (i.e., the time for boat transport between field and ripening store) depending on the areas being considered. If fruits ripen during transport, they cannot be sold and they endanger the whole container (i.e., the ethylene emitted by ripe fruit causes the induction of ripening in other fruit). Thus, it is a key issue to harvest fruit with a green-life that matches the expected time for transport.

The green-life of bananas is their major post-harvest attribute. It is the time between harvest and the moment the fruit becomes ripe. Bananas are a climacteric fruit, characterised by a rapid increase in ethylene production and respiration at the maturation stage. Bugaud and Lassoudière (2005) demonstrated that the green-life of banana decreased with the number of heat units accumulated during the flowering-to-harvest (FHI) interval. Some diseases can also alter the green-life of banana fruit; for example, black Sigatoka disease, caused by the pathogenic fungus Mycosphaerella musicola Leach, reduces the green-life of Cavendish bananas (Chillet et al., 2009). As with other fruit such as pineapple (Montero-Calderón et al., 2008), packing conditions can also influence shelf-life. Nevertheless, in the case of banana, these conditions are highly standardised.

*Author for correspondence.
Export markets for dessert banana are based almost entirely on Musa spp., AAA group, cv. Cavendish Grande Naine. New cultivars selected for export markets must have good transportability, and be appreciated for their taste and aesthetic aspects in order to be accepted by the commodity chain and by consumers. In this paper, we focus on pink banana [Musa spp., AAA group, Red sub-group, cv. Figue Rose Naine (Daniells et al., 2001)]. This cultivar has novel properties in terms of market diversification because it has a different taste and colour. According to producer regions, farmers choose the date for harvesting bananas based on empirical observations of fruit diameter, or on the number of heat units $\left({ }^{\circ} \mathrm{Cd}\right)$ accumulated during the FHI. Jullien et al. (2008) showed that empirical methods based on fruit size can lead to ripening during transport, while methods based on accumulated heat units above a given threshold during FHI are more precise, reliable, and minimise the risk of ripening.

The present study aims to define the physiological characteristics of pink banana, including its temperature threshold and the relationship between its green-life and the physiological age $\left({ }^{\circ} \mathrm{Cd}\right)$ of the fruit. We established the number of heat units $\left({ }^{\circ} \mathrm{Cd}\right)$ that optimised the balance between the green-life required for transport, and fruit growth to maximise yield. We present a single simple application for two contrasting climatic areas in Martinique. 


\section{MATERIALS AND METHODS}

Determination of the temperature threshold

The temperature threshold is the temperature which, when subtracted from the mean daily temperature, optimises the heat units $\left({ }^{\circ} \mathrm{Cd}\right)$ accumulated between two specific physiological stages. We determined the temperature threshold of pink banana using regression between the heat units $\left({ }^{\circ} \mathrm{Cd}\right)$ accumulated above $0^{\circ} \mathrm{C}$ between the times of flowering and ripening [i.e., the flowering-to-ripening interval (FRI)] and the FRI (in d). Ripening is when the first fruit turns yellow. The slope of this regression corresponded to the temperature threshold (Arnold, 1959; Ikemoto and Takai, 2000.). We used a dataset for 13 plants grown at the research station of Petit-Morne, Martinique (50 m asl; $14^{\circ} 37^{\prime} 15.31^{\prime \prime} \mathrm{N}$; 60 $60^{\circ}$ 09.80"W) with a mean annual temperature of $26.3^{\circ} \mathrm{C}$, and four plants grown at the research station of Neuchâteau, Guadeloupe (250 m asl; $\left.16^{\circ} 04^{\prime} 52.20^{\prime \prime} \mathrm{N}, 61^{\circ} 36^{\prime} 03.44^{\prime \prime} \mathrm{W}\right)$ with a mean annual temperature of $24.6^{\circ} \mathrm{C}$. Different harvest dates and the different climatic conditions allowed us to explore a wider range of FRI values (between $90-152$ d).

\section{Growth conditions}

Two plots in Martinique were studied: Saint-Esprit (SE) at $14^{\circ} 34^{\prime} 08.69^{\prime \prime} \mathrm{N} ; 60^{\circ} 56^{\prime}$ 02.34"W (mean annual temperature $26.5^{\circ} \mathrm{C}$ ) and Vauclin (VA) at $14^{\circ} 33^{\prime} 31.32^{\prime \prime} \mathrm{N}$; $60^{\circ} 51^{\prime} 19.14^{\prime \prime} \mathrm{W}$ (mean annual temperature of $26.3^{\circ} \mathrm{C}$ ). Both fields were planted with suckers of Musa spp., AAA group, Red sub-group, cv. Figue Rose Naine and were grown without any biotic stress conditions (i.e., using pesticide treatments to control pathogens such as plantparasitic nematodes and Yellow Sigatoka disease) and with optimum fertilisation. The SE plot was measured during the first cropping cycle, while the VA plot was measured during the fifth cropping cycle. The mean temperatures of both plots were measured using Tinytag sensors (Gemini Data Loggers $^{\mathrm{TM}}$, Chichester, UK) under standardised conditions. The physiological age of the fruit was expressed in heat units $\left({ }^{\circ} \mathrm{Cd}\right)$ accumulated since inflorescence emergence (i.e., flowering) and corresponded to the sum of daily temperatures above the temperature threshold (Bonhomme, 2000).

\section{Fruit sampling and post-harvest observations}

We sampled 62 bunches, with a cluster of four fruit taken from the middle of the second hand from the top of each

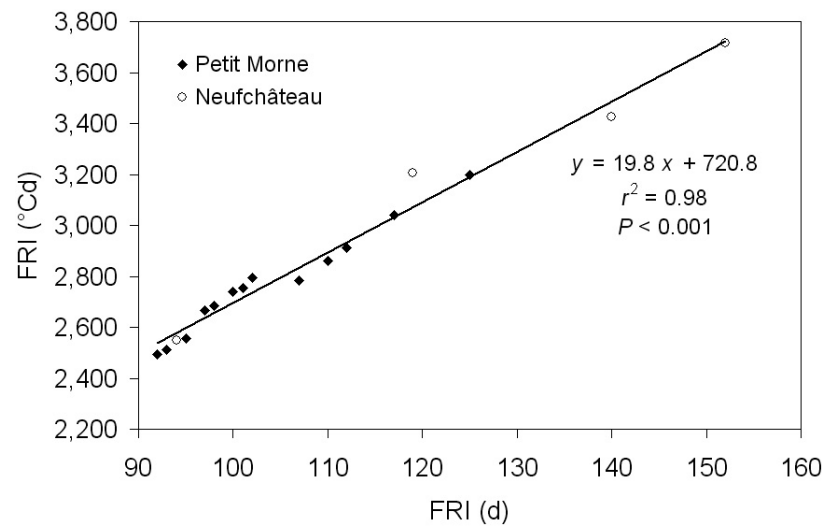

FIG. 1

Relationship between FRI in heat units accumulated above $0{ }^{\circ} \mathrm{C}$ and FRI in d, using data from Neufchâteau (Guadeloupe) and Petit-Morne (Martinique). The slope $\left(19.8^{\circ} \mathrm{C}\right)$ of the regression corresponds to the temperature threshold of pink banana. bunch. We harvested fruit with ages varying from $49-112 \mathrm{~d}$. After harvest, all fruits were treated with fungicide to prevent the development of fungi such as Colletotrichum musae. All fruits were then weighed and packed in separate perforated polybags to prevent desiccation and contamination by ethylene. Finally, the fruits were stored in ventilated climatic chambers set at $14^{\circ} \mathrm{C}$. These standard conditions were designed to mimic the sea-transportation of bananas from producer country to importing country in reefer containers (i.e., refrigerated independent containers). Preliminary trials showed that the skin of pink banana was not damaged by storage at $14^{\circ} \mathrm{C}$. The end of green-life, corresponding to the climacteric peak, was defined by the time-point when fruit firmness suddenly decreased (measured manually each day) and when the fruit turned yellow for Cavendish cultivars, or clear pink for pink banana.

\section{Temperature datasets}

We established two temperature datasets using mean values between 2004 and 2008 for the two representative production areas on Martinique, using a meteorological station (Campbell Scientific ${ }^{\mathrm{TM}}$, Shepshed, UK). These were: (i) at low altitude $(50 \mathrm{~m})$, similar to the area studied with a mean annual temperature of $26.3^{\circ} \mathrm{C}$; and (ii) at higher altitude $(250 \mathrm{~m})$, with a lower mean annual temperature of $23.8^{\circ} \mathrm{C}$.

\section{Statistics}

Equation fitting and $95 \%$ prediction interval envelope curves were performed using Table Curve 2D 5.0 (Systat Software Inc., London, UK). The lower 95\% prediction interval envelope curve ensured that fruit of a given physiological age had a $95 \%$ probability of being equal to or exceeding the green-life of the regression. Analyses of co-variance (ANCOVA) were performed using R software Version 2.90 (R Foundation for Statistical Computing, Vienna, Austria).

\section{RESULTS AND DISCUSSION}

Temperature threshold and variation in the green-life of pink banana

We determined the temperature threshold of pink banana to be equal to $19.8^{\circ} \mathrm{C}$ (Figure 1). The relationship

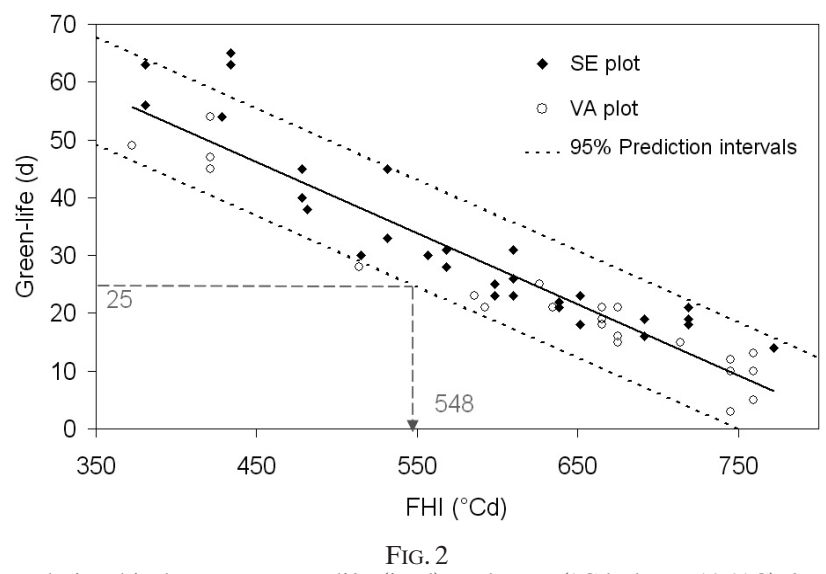

Relationship between green-life (in d) and FHI $\left({ }^{\circ} \mathrm{Cd}\right.$ above $19.8^{\circ} \mathrm{C}$ ) for pink banana fruit from the SE and VA plots. The solid line is the regression with the whole dataset, and the dotted lines are the $95 \%$ prediction interval curves. The grey dashed lines present the way to calculate the FHI $\left({ }^{\circ} \mathrm{Cd}\right.$ above $19.8^{\circ} \mathrm{C}$ ) that ensures a green-life of $25 \mathrm{~d}$. 
used was highly significant $(P<0.001)$ and held over a wide range of FRI values.

The green-life of fruit was between $5-65 \mathrm{~d}$, and decreased with physiological age (Figure 2). The distribution was linear $\left(r^{2}=0.90\right.$; ANCOVA; $\left.P<0.001\right)$, and the two sites were not significantly different (ANCOVA; $P=0.182$ ). Thus, crop cycle did not influence the relationship. The relationship established for pink banana followed the same trend as Cavendish cultivars (Bugaud et al., 2006; Jullien et al., 2008). The lower 95\% prediction interval envelope curve served to determine the optimum physiological age at which fruit should be harvested in order to minimise the risk of ripening during transport, and to maximise fruit size. Thus:

Green-life $=0.123 \times$ fruit physiological age +92.4

For instance, when exporting bananas from the French West Indies to Europe, $25 \mathrm{~d}$ are required, and the fruit should be harvested before $548{ }^{\circ} \mathrm{Cd}$ above $19.8^{\circ} \mathrm{C}$ had accumulated. For a green-life of $25 \mathrm{~d}$, the physiological age of the fruit varied between $543-696{ }^{\circ} \mathrm{Cd}$ above $19.8^{\circ} \mathrm{C}$, within the $95 \%$ prediction interval envelope curves. This range was equivalent to $3-4$ weeks in the mean climate $\left(26^{\circ} \mathrm{C}\right)$ and corresponded to the usual range of harvest dates for fruit that emerged in any given week.

Green-life decreased when the fruit weight was greater (Figure 3). However, the relationship differed significantly between the two plots (ANCOVA; $P<0.001)$. This result was consistent with the findings of Bugaud et al. (2006) for Cavendish bananas. This difference can be explained by the fact that fruit from the first cropping cycle (SE plot) were generally larger in weight than fruit from the second or later cropping cycles (VA plot). For a green-life of $25 \mathrm{~d}$, we observed a wide range of fruit weights (i.e., $66-228 \mathrm{~g}$ ) inside the $95 \%$ prediction interval envelope. Thus, fruit weight and, as a consequence, fruit diameter were not reliable variables with which to select fruit for harvest.

\section{Determination of optimum harvest date}

For the two temperature datasets (at $50 \mathrm{~m}$ and $250 \mathrm{~m}$ ), and for every possible week of flowering, we calculated the FHI value that allowed fruit to reach, but not exceed, the threshold of $548{ }^{\circ} \mathrm{Cd}$ above $19.8^{\circ} \mathrm{C}$. This case study highlighted the variation in FHI due to site and to seasonal variations in temperature (Figure 4). Shorter FHI values were observed at the two sites during the warm season, between weeks $19-33$. We observed less

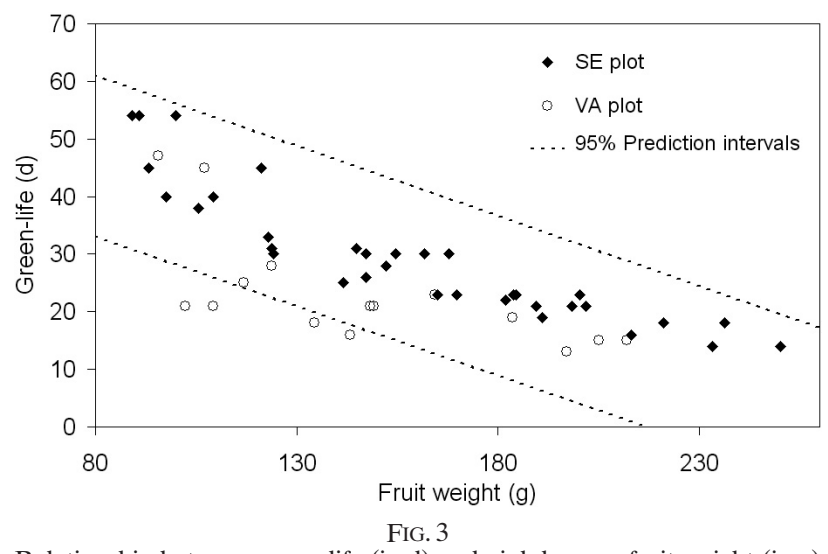

Relationship between green-life (in d) and pink banana fruit weight (in g) for the SE and VA plots. The dotted lines are the $95 \%$ prediction intervals. difference in FHI values between the two sites during the warm period (i.e., 5 weeks) than during the cold period (i.e., $\leq 13$ weeks).

Our results lead to direct recommendations for farmers who grow pink bananas for export. Choosing the optimum harvest date allows them to minimise the risk of ripening during export and to maximise fruit size. Our results show the importance of adjusting the FHI in realtime, based on temperature measurements. Farmer practices should include this element.

\section{Export potential of pink banana and further studies required}

We measured the temperature threshold and showed, for the first time, data on the relationship between FHI and the green-life of pink banana. These results will help banana growers to promote this cultivar of banana, which may segment the banana market. Determining the precise FHI is a key element in maintaining fruit quality all year round. Respecting the FHI requires precise tagging of each bunch at its precise flowering stage. In order to produce fruit of a consistently high quality, research could be carried out (as on other fruit) to extend the green-life of pink banana. For example, Raybaudi-Massilia et al. (2007) showed that aqueous solutions of $\mathrm{N}$-acetyl-1-cysteine, glutathione, calcium lactate, or $D$-1-malic acid reduced ethylene concentrations in apple.

Some improvements could also be achieved by taking farm-level constraints into account (e.g., availability of labour) and by simulating yield variations over successive years for pink banana. Another promising approach would be to link our model based on temperature to more complex models that simulate the growth of fruit and the distribution of flowering stages over many years (e.g., the SIMBA-POP model; Tixier et al., 2004), or more comprehensive modelling tools for cropping systems (e.g., SIMBA framework; Tixier et al., 2008). Such tools will help farmers to optimise the management of their pink banana fields.

We are grateful to Mr. Jenny (CIRAD) for the data from Neufchâteau in Guadeloupe and Dr. Duyck (CIRAD) for correction of the manuscript. We also thank the farmers from Martinique, especially Mr. Bertome and Mr. Delem, for access to their banana fields. Finally, we thank Mr. Banidol (CIRAD) for his technical assistance.

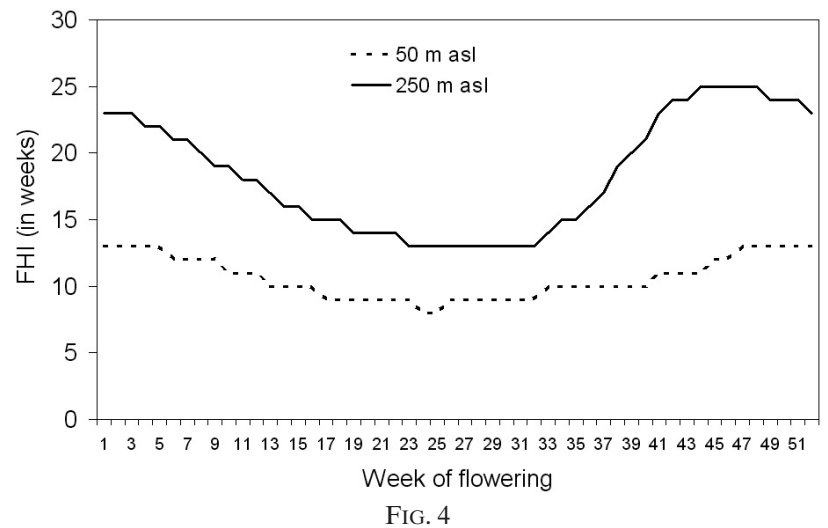

Optimum FHI values according to the week of flowering (week-1 was the first week of January) to ensure a green-life of $25 \mathrm{~d}$ for pink banana in two production areas in Martinique (at $50 \mathrm{~m}$ and $250 \mathrm{~m}$ asl.). 


\section{REFERENCES}

ARnOLD, C. Y. (1959). The determination and significance of the temperature threshold in a linear heat unit system. Proceedings of the American Society for Horticultural Science, 74, 430-445.

Bonhomme, R. (2000). Bases and limits to using 'degree.day' units. European Jounal of Agronomy, 13, 1-10.

Bugaud, C. and Lassoudiere, A. (2005). Variabilité de la durée de vie verte des bananes en conditions réelles de production. Fruits, 60, 1-10.

Bugaud, C., Chillet, M., Beauté, M. P. and Dubois, C. (2006) Physicochemical analysis of mountain bananas from the French West Indies. Scientia Horticulturae, 108, 167-172.

Chillet, M., Abadie, C., Hubert, O., Chilin-Charles, Y. and De Lapeyre De Bellaire, L. (2009). Sigatoka disease reduces the greenlife of bananas. Crop Protection, 28, 41-45.

Daniells, J., Jenny, C., Karamura, D. and TomekPe, K. (2001) INIBAP Musalogue Diversity in the Genus Musa. $207 \mathrm{pp}$. (http://bananas.bioversityinternational.org/files/files/pdf/ publications/musalogue2.pdf)

FAOSTAT (2005). Statistical Databases. (http://faostat.fao.org/faostat)

IKEMOTO, T. and TAKAI, K. (2000). A new linearized formula for the law of total effective temperature and the evaluation of linefitting methods with both variables subject to error. Environmental Entomology, 29, 671-682.
Jullien, A., Chillet, M. and Malézieux, E. (2008). Pre-harvest growth and development, measured as accumulated degree days, determine the post-harvest green-life of banana fruit. Journal of Horticultural Science \& Biotechnology, 83, 506-512.

Montero-Calderóna, M., Alejandra Rojas-Graüb, M. and MARtín-Belloso, O. (2008). Effect of packaging conditions on quality and shelf-life of fresh-cut pineapple (Ananas comosus). Post-Harvest Biology and Technology, 50, 182-189.

Raybaudi-Massilia, R. M., Mosqueda-Melgar, J., SobrinoLópez, A., Soliva-Fortuny, R. and Martín-Belloso, O. (2007). Shelf-life extension of fresh-cut 'Fuji' apples at different ripeness stages using natural substances. Post-Harvest Biology and Technology, 45, 265-275.

Tixier, P., MalézieuX, E. and Dorel, M. (2004). SIMBA-POP: a cohort population model for long-term simulation of banana crop harvest. Ecological Modelling, 180, 407-417.

Tixier, P., MalézieuX, E., Dorel, M. and Wery, J. (2008). SIMBA a comprehensive model for evaluation and prototyping of banana-based cropping systems. Agricultural Systems, 97, $139-150$. 